This is the author's final, peer-reviewed manuscript as accepted for publication. The publisher-formatted version may be available through the publisher's web site or your institution's library.

\title{
Marital therapy help-seeking attitudes of young adults in mainland China
}

Rebekah D. Adams, C. J. Aducci, Jared R. Anderson, Matthew D. Johnson, Fuming Zheng, Wenli Liu

\section{How to cite this manuscript}

If you make reference to this version of the manuscript, use the following information:

Adams, R. D., Aducci, C. J., Anderson, J. R., Johnson, M. D., Zheng, F., \& Liu, W. (2013). Marital therapy help-seeking attitudes of young adults in mainland China. Retrieved from http://krex.ksu.edu

\section{Published Version Information}

Citation: Adams, R. D., Aducci, C. J., Anderson, J. R., Johnson, M. D., Zheng, F., \& Liu, W. (2013). Marital therapy help-seeking attitudes of young adults in mainland China. The American Journal of Family Therapy, 41(1), 63-71.

Copyright: Copyright $\odot$ Taylor \& Francis Group, LLC

Digital Object Identifier (DOI): doi:10.1080/01926187.2011.638573

Publisher's Link: http://www.tandfonline.com/doi/abs/10.1080/01926187.2011.638573

This item was retrieved from the K-State Research Exchange (K-REx), the institutional repository of Kansas State University. K-REx is available at http://krex.ksu.edu 
Marital Therapy Help-Seeking Attitudes of Young Adults in Mainland China

*Rebekah D. Adams, C. J. Aducci, Jared R. Anderson, Matthew D. Johnson

*Denotes equal authorship of first four authors, listed in alphabetical order of last name

Kansas State University

Fuming Zheng

South China Normal University

Wenli Liu

Beijing Normal University

Rebekah D. Adams, C. J. Aducci, Jared R. Anderson, Matthew D. Johnson, School of Family Studies and Human Services, Kansas State University; Fuming Zheng, Department of Early Childhood Education, South China Normal University; Wenli Liu, State Key Laboratory of Cognitive Neuroscience and Learning, Beijing Normal University.

Acknowledgements: The authors would like to thank Gang Wang, J. Kale Monk, Elisabeth Beam, Rachael Rutter, and Amy Hodgdon for their contributions to this research project.

Correspondence concerning this article should be addressed to Jared R. Anderson, School of Family Studies and Human Services, Kansas State University, 209 Campus Creek Complex, Manhattan, KS 66506. E-mail: jra@ksu.edu. Phone: 785-532-4198.

Keywords: Mainland China, help-seeking, marital therapy, young adults 


\begin{abstract}
Using qualitative interview data from young adults in Mainland China $(n=24)$, the current study explored help-seeking attitudes toward marital therapy. In general, significant relationship problems that participants labeled as communication difficulties, emotional distance, and thoughts of divorce were seen as legitimate reasons to seek out marital therapy. Nearly all participants reported that before seeking out professional services, they would first talk to friends and family members, and only if problems did not abate or continued to be a significant risk to relationship harmony and stability would they be open to seeking out professional services. Finally, the participants generally believed that their family and friends would support their decision to access marital therapy services. The results from this study point to the importance of developing effective, culturally relevant approaches to the treatment of marital distress in Mainland China.
\end{abstract}


Mental health practice in the People’s Republic of China (PRC) has experienced significant growth over the last two decades, although it remains in the early stages of development (Qian, Smith, Chen, \& Xia, 2001). At the same time, the PRC has experienced rapid economic and societal changes since the market-economy reforms (Chang et al., 2005). One of these societal changes is the PRC's divorce and remarriage rates, which have each increased over 200\% since 1979 and are expected to continue rising at a "significant rate” (Wang \& Zhou, 2010, p. 266). Increasing marital instability and distress could suggest a need for increased availability of marital therapy services from systemically trained therapists.

On the other hand, research from one family therapy center in Beijing reported that couples therapy was the least sought out therapy modality, comprising only $6 \%$ of all cases. This was compared to family therapy (67\% of cases) and individual therapy (27\%) (Sze, Hou, Lan, \& Fang, 2011). In addition, studies of young adults in the PRC have found a pervasive stigma attached to marital therapy services (Anderson et al., in press), in part, because seeing a mental health professional is more acceptable if the cause is perceived to be out of one's control (as with a hereditary or environmental problem), than for problems such as interpersonal difficulties (Chen \& Mak, 2008). While the Chinese traditionally try to handle problems within the family (Lim, Lim, Michael, Cai, \& Schock, 2010), it is plausible that increased family instability due to the rising divorce and remarriage rates may lead young adults to seek more formal, professional sources of information to deal with their marital and relationship problems. The current study seeks to add an important piece to the growing literature around marital therapy in China (see Sim \& Hu, 2009) by answering the following research questions:

1. What problems would lead individuals to seek marital therapy in Mainland China?

2. Who would the individual choose to include in marital therapy? 


\section{Method}

\section{Participants}

Participants $(N=24)$ were recruited from two large urban universities, were comprised of undergraduate and graduate students and ranged in age from 19-27 $(M=22.17 ; S D=2.75)$ with

nearly equal numbers of men (11) and women (13). All participants were at least 18 years old and currently involved in a romantic relationship that was expected to continue. Although the participants were drawn from a convenience sample, this sample may consist of individuals most likely to seek out and have access to marital therapy services (based on education, financial resources, and location in large, urban centers).

\section{Interview Procedures \& Data Analysis}

Students were made aware of the study through campus advertisements and were instructed to contact WL and FZ (authors) of their interest to participate. Three translators were recruited at each university to provide a verbatim translation of the interview questions and of the participants' responses during interviews that were conducted by the English-speaking researchers. All interviews were conducted by the authors and all adhered closely to the interview guide. Interviews averaged between 60 and 90 minutes in length.

A coding scheme developed by Auerbach \& Silverstein (2003) was used by the researchers to analyze the data. This method involved identifying pieces of relevant text in the raw text (transcripts), followed by merging the relevant text into repeated ideas, which were then grouped into themes. Relevant text can be defined as any statement made by a participant that potentially answers any one of the research questions or allows the researchers to understand the participant(s) better (Auerbach \& Silverstein, 2003). Working independently, six researchers analyzed the raw text to identify relevant text from all 24 interviews. Pieces of relevant text that 
were noted by at least two researchers were then labeled as a repeated idea. Finally, the researchers worked collaboratively to develop the repeated ideas into the themes, which represent the major findings of this study. Working independently and collaboratively to code the data among six different researchers helped to ensure triangulation of the data.

\section{Results}

\section{Reasons to Seek Marital Therapy}

Marital distress, emotional distance, and the threat of marital dissolution emerged as key problems in marriage that participants felt would warrant seeking marital therapy services.

General marital distress. Participants commonly described general marital distress as partners' inability to understand each other and frequent arguing. This lack of understanding was described as an “inability to see the other's point of view” stemming from differences in communication styles or personality. Another participant described this lack of understanding as “having different opinions on important things,” such as how many children to have or whether to further the education of one or both spouses. Arguing was another type of marital distress that participants' believed would lead a couple to seek marital therapy. Brief repeated ideas about arguing included "have conflict,” “don’t agree with one another,” and “always quarreling.” Some participants mentioned arguing might begin with small disagreements that would eventually develop into larger problems. For example, one participant stated:

People usually quarrel about very tiny things, such as, who should buy the vegetables? Who should pick up the children? Which parent's house should we visit for the Chinese New Year? These problems may not be solved in time and may become big problems. Arguing was often said to exist when couples did not agree with one another or had complaints about each other. Specifically, two participants mentioned complaints about each 
other's "weaknesses” and "habits.” These participants noted that a couple should seek therapy when the couple is unable to manage these complaints themselves.

Emotional distance. Another subtheme that emerged was related to emotional distance. Participants shared that couples would seek services if the couple became emotionally distant and experienced a loss of love. Brief repeated ideas include, “don’t feel as before,” “not feeling comfortable living with one another [any longer]," "bad feelings toward each other," and “a break in the relationship.” One participant put it this way: "two persons live together, then, as time goes on, the love between [them] may become less and less.” Another participant shared, “[if there is] not enough time spent together, they may forget each other."

Threat of marital dissolution. The final subtheme for problems that would lead to the use of marital therapy services is the threat of the relationship ending. Words like "considering," “thinking about” and "wanting” divorce all came up when participants described situations which would warrant the use of these services. Participants specifically discussed the possibility of divorce as being a key reason for seeking help. One participant stated: "the stage when one of them mentions divorce [is when] they may come to therapy...”

In addition to these three themes, there were a handful of notable reasons mentioned by participants, but that did not represent common themes across the majority of participants. These problems included sexual difficulties, financial problems, conflict with family of origin, differences in parenting style, infidelity, and intimate-partner violence.

\section{Who to Include in Marital Therapy}

Participants noted they would also seek help from close friends or family members to help correct relationship problems and that the presence of a friend or family member in a 
marital therapy session could enhance the therapy experience. The participants also noted that these persons would generally support the couple in their efforts to seek marital therapy.

Normative help-seeking outlets. Participants reported that they would talk to friends and family members first if they were to experience problems in their future marriages. Participants described being very intentional regarding which friends and family members would be included in their problems. Participants reported choosing individuals who could provide objectivity and who could be placed in an expert position by having a certain amount of relational experience. Common repeated ideas reported by participants included "friends who are familiar with both of them [couple]," “friends with much experience,” “more objective,” and “elder member.” When asked where he would go for advice, one participant stated: "Where? To my parents, because I think they have a very harmonious relationship. I think they are doing a good job.” Another participant shared; "My friend, my friend who has the same problem, or some experience in marriage.” Regarding a desire for someone to be objective, one participant said: “only when the friends are quite familiar with the couple and the situation...”

Who to Include in Marital Therapy. While participants reported a willingness to seek advice from friends and family members about relationship issues, they were divided regarding whether or not it was acceptable to include them in therapy. Some participants believed that a friend or family member would be useful to the couple in therapy to make sure they speak the truth. One participant said: “they [couple] cannot describe their problems objectively; the girl’s sister who knows them very well will help the therapist to know "what's the problem.” Another participant stated: “parents will be invited to therapy because they know more about you, your relationship with the other, and your happiness.” Reasons against including anyone other than 
the couple were related to the issue of privacy. Repeated ideas included phrases such as 'nothing to do with anyone else,' 'two is enough,' 'it's their own problems,' and 'it’s private.'

Network Support in Seeking Marital Therapy. In general, participants reported that their families would be supportive, or at least open to the couple seeking formal marital therapy services. Several participants described their families as being supportive and open to the experience. Other participants used words like “would not oppose” and "they will respect my choice.” The perceived magnitude of the problem also emerged as a key distinguishing factor in the family accepting or not accepting marital therapy. One participant stated: "If there were some small problems between my partner and me, then my parents may not think it necessary. But if there is really...big problems then they may think you should go.”

\section{Discussion and Clinical Implications}

The purpose of the current study was to explore help-seeking attitudes toward marital therapy among a cohort of young adults in the People’s Republic of China. Specifically, we explored what relational problems would lead them to seek marital therapy, who they would choose to include in marital therapy, and whether they believed their family would support the decision to attend marital therapy. Related to the first question, a lack of understanding each other, frequent arguing, the development of emotional distance between partners, and the threat of divorce were all cited as relationship issues suggestive of accessing marital therapy services. These findings are similar to those of Doss and colleagues (2004), who found that a lack of emotional affection, problematic communication, and concerns about divorce or separation were primary reasons couples sought marital therapy in the U.S.

The participants in this study reported that they would first turn to family members and friends who they respected, who could be objective and impartial, and who had experience in a 
relationship/marriage, or their particular problem, before they would seek out a professional. This is consistent with previous literature that finds that Chinese young adults have a great deal of respect for their parents (McLaughlin \& Braun, 1998) and are likely to seek out their parents for help first when encountering a mental health issue (Lee \& Mock, 2005). Turning toward parents and respected elders may help to strengthen family ties and provide the young couple with wise counsel, however it may increase worry and emotional strain on these parents, or increase conflict within the family as the marital wisdom of the parent's generation collides with the expectations and beliefs of the younger generation. This potential generational divide on relational issues is now more likely to occur, given the changing family dynamics related to the one child policy (Shi \& Scharff, 2008) and to the changing values due to rapid industrialization and modernization (Chang et al., 2005). Therefore, a marital problem in one generation could have implications for treating additional family members other than just the presenting couple. Participants seemed to agree that their friends and families would be open to them utilizing services, and for some, that inclusion of these key support figures would be important to the marital therapy process. Others felt that it would be unnecessary to include family and friends in therapy unless they had lost the ability to talk openly and objectively about the problem. Due to the cultural deference to authority in Chinese society, it is possible that clients will not be as active in verbalizing what they prefer from treatment, being more comfortable to allow the therapist to direct treatment (Qian et al., 2001). Therefore, clinicians should be advised that in some instances Chinese couples may prefer to involve members of their larger support system in the treatment of marital problems, but may be hesitant to voice this preference out of a concern of offending the therapist. Informing the couples that friends and other extended kin are welcome to participate with the couple in therapy may help to ease the couples' comfort level and increase 
their willingness to continue with therapy. To accommodate for this, clinicians may need to rethink their assumptions about the qualities accounting for high functioning marriages. For instance, what could be seen as triangulating other family members or enmeshed boundaries within White or Western couples, may be appropriate in Chinese culture. Another strategy that therapists in the PRC could use to engage couples in marital therapy is to convey the strong research link between marital quality and child outcomes. The marriage often takes a distant back seat to child rearing and child focused family therapy cases tend to predominate in current clinical practice in the PRC (Sze et al., 2011). By linking marital quality to child outcomes, Chinese couples may be more likely to access marital therapy services in order to strengthen their relationship as one way to strengthen their child's outcomes. Finally, given the concerns regarding stigma, marriage education and on-line or tele-therapy may also provide additional, less intrusive mechanisms for delivering marital strengthening interventions to couples in need.

\section{Limitations and Conclusion}

The findings should be viewed while considering the limitations of the study. First, the study included a convenience sample of Chinese young adults in committed relationships currently attending university; therefore, they are a unique group among young adults in China. On the other hand, this group of participants will have the economic means and live in a geographic region that will enable them to access such services in the future, if they so choose. Therefore, the sample does include individuals who are most likely to be open to and able to afford professional marital therapy and thus, their beliefs and values regarding marital therapy are particularly salient. Second, the use of translators to assist in the qualitative interviews could be seen as a limitation. To combat this limitation, translators were native Chinese fluent in English and were directed to provide a word for word translation of the participant's responses. 
Finally, we used multiple interviewers in the process of data collection as a result of our relatively large sample and the timeframe we had to conduct the interviews. This process likely created some variability in the interview process. In order to limit this variability, significant discussions occurred related to the meaning and purpose of each question and all interviewers met to debrief after each "round" of interviews.

For a group of young adults from the PRC, significant relationship problems they labeled as communication difficulties, emotional distance, and thoughts of divorce were legitimate reasons to seek out marital therapy. Further, participants reported that they would seek out key friends and family members first, and only if problems did not abate or were significant risks to the relationship, would they be open to seeking out professional services. In addition, some participants desired to include family and/or friends in the marital therapy process, while others believed it should only involve the couple. Finally, the participants generally believed that their family would support their decision to seek professional services and would trust their judgment in the matter. The results from this study point to the importance of developing effective, culturally relevant approaches to the treatment of marital distress in Mainland China.

\section{References}

Anderson, J. R., Aducci, C. J., Adams, R. D., Johnson, M. D., Liu, W., Zheng, F., \& Ratcliffe, G. C. (in press). Attitudes and beliefs about marital therapy among university students in Mainland China. Journal of Family Psychotherapy.

Auerbach, C. F., \& Silverstein, L. B. (2003). Qualitative data: An introduction to coding and analysis. New York: New York University Press.

Chang, D. F., Tong, H., Shi, Q., Zeng, Q. (2005). Letting a hundred flowers bloom: Counseling and psychotherapy in the People’s Republic of China. Journal of Mental Health 
Counseling, 27, 104-116.

Chen, S. X., \& Mak, W. W. S. (2008). Seeking professional help: Etiology beliefs about mental illness across cultures. Journal of Counseling and Clinical Psychology, 55, 442-450.

Doss, B. D., Simpson, L. E., \& Christensen, A. (2004). Why do couples seek marital therapy? Professional Psychology: Research and Practice, 35, 608-614.

McGlaughlin, L. A., \& Braun, K. L. (1998). Asian and Pacific Islander cultural values: Considerations for health care decision making. Health and Social Work, 23, 116-126.

Lee, E., \& Mock, M. R. (2005). Chinese families. In M. McGoldrick, J. Giordano, and N. Garcia-Preto (Eds.), Ethnicity and family therapy (pp. 302-318). New York: Guilford.

Lim, S. L., Lim, B. K. H., Michael, R., Cai, R., \& Schock, C. K. (2010). The trajectory of counseling in China: Past, present, and future trends. Journal of Counseling and Development, 88, 4-8.

Qian, M., Smith, C. W., Chen, Z., \& Xia, G. (2001). Psychotherapy in China: A review of its history and contemporary directions. International Journal of Mental Health, 50, 49-68.

Shi, Q., \& Scharff, J. S. (2008). Social change, intercultural conflict, and marital dynamics in a Chinese marriage in brief concurrent individual and couple therapy. International Journal of Applied Psychoanalytic Studies, 5, 302-321.

Sim, T., \& Hu, C. (2009). Family therapy in the Forbidden City: A review of Chinese journals from 1978 to 2006. Family Process, 48, 559-583.

Sze, Y. T., Hou, J., Lan, J., \& Fang, X. (2011). Profiling family therapy users of a therapy center in Beijing. The American Journal of Family Therapy, 39, 299-306.

Wang, Q. \& Zhou, Q. (2010). China’s divorce and remarriage rates: Trends and regional disparities. Journal of Divorce \& Remarriage, 51, 257-267. 